\title{
Affordability issues of biotech drugs in low- and middle-income countries
}

\author{
Abdul Kader Mohiuddin \\ Department of Pharmacy, World University of Bangladesh, 151/8, Green Road, Dhanmondi, Dhaka - 1205, Bangladesh. \\ Email: mohiuddin3@pharmacy.wub.edu.bd; Tel: +8801716477485. \\ Copyright @ 2019 Mohiuddin. This article remains permanently open access under the terms of the Creative Commons Attribution License 4.0, which \\ permits unrestricted use, distribution, and reproduction in any medium, provided the original work is properly cited.
}

Received 22nd July, 2019; Accepted 26th July, 2019

\section{Respected sir,}

Pharmaceutical companies invest in the development and testing of their drugs including funding clinical trials. Furthermore, pharmaceutical companies also spend a large amount of money on advertising. For instance, in 2016 US $\$ 6.7$ billion was spent on direct-to-consumer pharmaceutical advertising alone in the USA (Beck et al., 2019). Worldwide spending on medicines reached $\$ 1.2$ trillion in 2018 and will exceed $\$ 1.5$ trillion by 2023 , according to "The Global Use of Medicine in 2019 and Outlook to 2023" (Philippidis, 2018; Aitken et al, 2019). Although, access to essential medicines is problematic for one third of all persons worldwide (Stevens and Huys, 2017). Limited access to essential medicines (EMs) for treating chronic diseases is a major challenge in low- and middle-income countries (LMICs) (Stevens and Huys, 2017; Faruqui et al., 2019). Average public sector availability of even low-cost generic medicines ranges from 30 to 55\% across 36 LMICs (Lexchin, 2013). Price of drugs, vaccines, and diagnostics is a major burden in 105 middle income countries round the globe, comprising of $70 \%$ of the world population, $75 \%$ of the poor (Moon, 2017). While public hospitals offer free or subsidized treatment including essential medicines, the high patient caseloads, underfunding and inefficient medicine distribution systems are barriers to consistent service provision (Prinja et al., 2015). Moreover, 90\% of the population in developing countries purchase medicines through out-of-pocket (OOP) payments (Moon, 2017). Poor availability of medicines in the public sector has pushed up household OOP expenditure, making them the largest household expenditure item after food (Oberoi and Oberoi, 2014). However, The WHO has set a minimum of $80 \%$ as target availability of medicines for both communicable and non-communicable diseases in all countries (Khuluza and Haefele-Abah, 2019). But Pharmaceutical companies have a substantial desire in developing drugs for chronic diseases and cancer treatments, not only because of high prevalence, but also because these drugs are often used in long term (Ahmadiani and Nikfar, 2016). Pharmaceutical patents maintain drug prices well above the cost of production and can restrict access to needed medicines ('t Hoen et al., 2018). Biotech drugs have completely changed the management of several diseases, including cancer and autoimmune diseases such as, psoriasis, rheumatoid arthritis, multiple sclerosis, and inflammatory bowel disease (Scavone et al., 2017). The high cost of biotech medications (target a gene or protein and typically are injected or infused, associated with treating a chronic condition) often requires significant OOP expenditures (Goldman et al., 2006; Vogenberg and Young, 2004). Some studies say that pharmaceutical companies price drugs monopolistically, protected by patent rights, while others believe that the high prices for orphan drugs simply allow drug $R$ \& $D$ and production costs. However, the global orphan drug market is estimated to reach US \$209 billion by 2022 accounting for $21.4 \%$ of total branded prescription drug sales (Jayasundara et al., 2019). According to the Tufts Center for Drug Development, it costs, on average, $\$ 100$ million in 1975 , around $\$ 900$ million before 2004 and 1.3 billion after 2005 to develop a new drug and bring it to market (Edelman, 2004; Kunnumakkara et al., 2019). While Scavone et al. (2019) reported that entire time that passes from the $R \& D$ phase until the drug's marketing approval can last up to 15 years, and it is characterized by extremely high costs, usually exceeding $\$ 1.2$ billion. Gouglas et al. (2018) estimated a minimum of $\$ 2.8$ to $\$ 3.7$ billion ( $\$ 1.2$ billion to $\$ 8.4$ billion range) for one vaccine through to the end of phase $2 \mathrm{a}$ among 11 epidemic infectious diseases. Apart from the traditional design of RCT, in recent years further study designs, including umbrella, basket and platform trials, 
were developed and applied to new therapies, especially in the area of oncology research (Simon, 2017). Tay-Teo et al. (2019) stated the most commonly accepted estimates of $R$ \& $D$ costs, including cancer drugs, are between $\$ 200$ million and $\$ 2.9$ billion, after adjustments for the probability of failure and opportunity costs. Genomic studies conducted in the past two decades identified the molecular drivers of certain cancers and led to the advent of targeted therapies as an important additional pillar of the cancer therapy armamentarium (Kaufman et al., 2019). According to the Global Oncology Trend Report, global spending on cancer medications rose from $\$ 75$ billion in 2010 to $\$ 100$ billion in $2014,10.3 \%$ rise in spending. Asia accounts for $60 \%$ of the world population and $50 \%$ of the global burden of cancer (Tay-Teo et al., 2019). There are over 100 types of cancers, located in different organs and sub-tissues and originating from different cell types. Some cancer types (e.g., colon, breast, and non-Hodgkin's lymphoma) contain even more specific classifications based on their molecular subtypes. Despite this complexity and variability, most types of cancer are treated with the same generic therapies (Chivukula and Tisocki, 2018). Critics claim that prices of innovative drugs are excessive and argue that lowering prices will not harm the flourishing innovation. On the opposite end, the pharmaceutical industry insists that restrictive pricing policies will have a detrimental impact on their ability to generate innovation (Krzyszczyk et al., 2018). During 2017, PIVI worked with its country partners and the WHO regional and local offices to assess NITAGs strengthening needs and to provide technical assistance in 7 LMICs (Laos Peoples Democratic Republic, Mongolia, Vietnam, Armenia, Côte d'Ivoire; Moldova and the Republic of Georgia) (Moreno and Epstein, 2019). In Europe, total cancer drug sales more than doubled between 2005 and 2014, increasing from $€ 8.0$ to $€ 19.8$ billion (Ba-Nguz et al., 2019). Biologics were estimated to account for US $\$ 289$ billion pharmaceutical sales in 2014 and are projected to reach US $\$ 445$ billion in 2019. It is also anticipated that biologics' share of global prescription and OTC pharmaceutical sales will rise to $26 \%$ by 2019 (Owoeye and Owoeye, 2018). It is projected that new cases of cancer will increase from about 14 million in 2012 to 22 million in 2030, with most cases in LMICs located in Africa, Asia and Latin America (Wilking et al., 2017). The projected increase in cancer incidence is predicted to be most significant in LMICs in Asia. In these countries, over $60 \%$ of the total healthcare expenditure comes from private resources, of which more than $80 \%$ is direct OOP payments, with catastrophic results for most families in these countries (Salmasi et al., 2017). In India alone, as many as 63 million people are forced into poverty every year, owing to catastrophic health expenses, the majority of which are OOP payments for medicines (Barrios et al., 2019). Genetic predisposition, increasing life expectancy, urbanization, mechanization, inadequate health services and rapid economic development fueling sedentariness and changing dietary patterns are contributing to rising chronic disease burden in the South Asian region (Paudel et al., 2019). Rijal et al. (2018) reported that Afghanistan, Bangladesh, Bhutan, Maldives, Nepal, India, Pakistan and Sri Lanka, which are mostly LMICs with regional GDP per capita 1640 USD and home to a quarter of world population (Rijal et al., 2018). According to Giri et al. (2018), breast cancer was the most prevalent cancer and fourth leading cause of cancerrelated mortality among women in Asia. Siegel et al. (2019) states mortality rates in the poorest counties were 2 -fold higher than most affluent counties for cervical cancer and $40 \%$ higher for male lung and liver cancers during 2012 to 2016. One-third of the world cervical cancer burden is endured in India, Bangladesh, Nepal and Sri Lanka. Highrisk HPV types were found in $97 \%$ of cervical cancers, and HPV-16 and 18 were found in $80 \%$ of cancers in India (Sankaranarayanan et al., 2008). Stomach cancer (9.0\%), breast cancer $(8.2 \%)$, lung cancer $(7.5 \%)$, lip and oral cavity cancer $(7 \cdot 2 \%)$, pharynx cancer other than nasopharynx $(6.8 \%)$, colon and rectum cancer $(5.8 \%)$, leukemia $(5 \cdot 2 \%)$, and cervical cancer $(5.2 \%)$ are the leading types of cancer in India in 2016 (Dhillon et al., 2018). India has been well known in the global oncology community as the country where cancer drug prices are cheaper compared to other countries. For instance, the 4weekly cost of trastuzumab was \$2761 in India versus $\$ 6849$ in the US (Gyawali, 2017). It was indeed heartening to see that India paid $\$ 19000$ for a 4-week course of bevacizumab (based on purchasing power parity) while Australia paid only $\$ 543$ (Goldstein et al., 2017). In the US, individuals diagnosed with cancer are 2.7 times more likely to declare bankruptcy, than individuals without cancer (Ramsey et al., 2013). Saqib et al. (2018) stated that patients in LMICs find it difficult to afford non-biologics and their treatment with new therapeutic agents like biologic is almost impossible. Therefore, the management of cancer is seriously affected by the availability and affordability of anticancer agents (Saqib et al., 2018). Due to lack of information on comparative drug prices and quality, it is difficult for physicians to prescribe the most economical treatment. Lack of information on quality, non-availability and conflicts of interest are also responsible for physicians not prescribing the least expensive medication. The difference in cost between the various brands of the same drug varies from 2- fold to more than 100 -fold in India (Kolasani et al., 2016). Bhutan (13\%), Maldives (5\%) and Timor-Leste (5\%) - are small countries with challenging geographies that lack the capacity for local pharmaceutical production. They may also use alternative strategies, such as sending patients with cancer for treatment abroad (Chivukula and Tisocki, 2018). Many examples of high drug prices exist and are frequently discussed in the media. One often mentioned example is imatinib (brand name Gleevec®), a drug for chronic myeloid leukemia, which tripled in cost after the US FDA allowed for a new indication. Novartis raised its price from $\$ 31,930$ in 2005 to $\$ 118,000$ per year in 2015 despite a huge increase in 
the volumes sold (van der Gronde et al., 2017). The 19th revision of the WHO EML in 2015 added 16 essential cancer drugs, including three high-cost medicines, imatinib, rituximab and trastuzumab, and therefore improving equitable access to innovative treatments for cancer that are widely unavailable in low-resource settings (Eniu et al., 2015). India is one of the top global funders of $R \& D$ into neglected diseases, according to Thomas et al. (2019). Nearly $12 \%$ of drug, diagnostic, and vaccine candidates for neglected diseases in the $R$ \& $D$ pipeline are from India (Thomas et al., 2019). Most South Asian countries have well laid out regulatory pathways for biosimilar approval. While no biosimilar insulin is approved in USA as of August 2015, the European Medicines Agency and Japanese drug regulatory authorities have given approval to only one insulin-a biosimilar insulin glargine produced by Kalra et al. (2016). One of the most significant safety concerns with biosimilars is the potential risk of immune-based adverse reactions. Because of their molecular size, biologics can directly induce anti-drug antibodies which may have significant consequences for both safety and efficacy (Mohiuddin, 2019). As manufacturers of biosimilar products do not have access to the cell line and technique of reference product, the manufacturing process may change slightly, but this may have tremendous impact on the biological function of the product, including immunogenicity, potentially affecting the safety and efficacy profile (Kaduskar, 2016). Also, the costs of drug distribution in India are 2 to 3 times greater than in the United States or the European Union, despite vastly lower labour costs. Their staff are not required to show skills in pharmaceutical warehousing and management, often with disastrous consequences (CUGPHISFCP, 2013). The monthly drug prices were the highest in the U.S and lowest in India. However, despite having the lowest drug prices, drugs were the least affordable (affordability estimated as drug prices divided by GDP per capita or average salary) in India (Kaduskar, 2016; CUGPHISFCP, 2013). Those drugs that ensure cure should be given the first priority. The governments and policy makers in LMICs should prioritize access to highly effective biotech drugs used in curative setting and limit spending on costly but ineffective or minimally effective drugs used in palliative setting. Inter collaborations between the BRICS countries like Brazil, China and India need to set the pace and create more incentives to increase local production of drugs with LMICs (Ezziane, 2014). There are various interventions or changes in policies advised that can help in lowering the cost of biotech drugs like breaking the monopoly in drug manufacturers, changing the regulatory guidelines by government agencies in favor of those companies which manufacture cheaper drugs and making the new drug approvals faster, increasing the cost effectiveness ratio of drugs, achieving a balance between physician autonomy in prescribing biotech drugs and costs incurred by patients, encouraging non-profit generic companies which manufacture biotech drugs by giving them tax incentives and other measures, value based reimbursement by medical insurance companies.

\section{CONFLICT OF INTEREST}

The author declares no competing interests.

\section{ACKNOWLEDGEMENT}

I am thankful to Gautam Kumar Saha, Apollo Hospitals Educational and Research Foundation, New Delhi, India for his precious time to review my letter to the editor and for his thoughtful suggestions. I am also grateful to seminar library of Faculty of Pharmacy, University of Dhaka and BANSDOC Library, Bangladesh for providing me books, journal and newsletters.

\section{ABBREVIATIONS}

Partnership for Influenza Vaccine Introduction (PIVI); National Immunization Technical Advisory Groups (NITAGs); Out-of-pocket (OOP); Low-and Middle-Income Countries (LMICs); Randomized Control Trial (RCT); Human Papillomavirus (HPV); Gross Domestic Product (GDP); Essential Medicine List (EML); Research and Development (R\&D); Brazil, Russia, India, China and South Africa (BRICS countries)

\section{REFERENCES}

Ahmadiani, S., \& Nikfar, S. (2016). Challenges of access to medicine and the responsibility of pharmaceutical companies: a legal perspective. DARU Journal of Pharmaceutical Sciences, 24(1), 13.

Aitken, M., Kleinrock, M., Simorellis, A., \& Nass, D. (2019). The global use of medicine in 2019 and outlook to 2023. Forecasts and Areas to Watch. Institute Report, January 29, 2019.

Ba-Nguz, A., Shah, A., Bresee, J. S., Lafond, K. E., Cavallaro, K., Shefer, A., Donadel, M., \& Seward, J. F. (2019). Supporting national immunization technical advisory groups (NITAGs) in resource-constrained settings. New strategies and lessons learned from the Task Force for Global Health's Partnership for influenza vaccine introduction. Vaccine, 37(28), 3646-3653.

Barrios, C. H., Reinert, T., \& Werutsky, G. (2019). Access to highcost drugs for advanced breast cancer in Latin America, particularly trastuzumab. Ecancermedicalscience, 13, 898.

Beck, E. J., Mandalia, S., DongmoNguimfack, B., Pinheiro, E., 't Hoen, E., Boulet, P., Stover, J., Gupta, A., Juneja, S., Habiyambere, V., \& Ghys, P. (2019). Does the political will exist to bring quality-assured and affordable drugs to low-and middle-income countries? Global Health Action, 12(1), 1586317.

Chivukula, M. V., \& Tisocki, K. (2018). Essential cancer medicines in the national lists of countries of the WHO SouthEast Asia Region: a descriptive assessment. WHO South-East 
Asia Journal of Public Health, 7(2), 90-98.

Committee on Understanding the Global Public Health Implications of Substandard, Falsified, and Counterfeit Medical Products (CUGPHISFCP) (2013). Weaknesses in the drug distribution chain. In: Countering the problem of falsified and substandard drugs. Buckley G. J., \& Gostin L. O. (eds.). Board on Global Health; Institute of Medicine, Washington (DC): National Academies Press (US). Available from: https://www.ncbi.nlm.nih.gov/books/NBK202523/

Dhillon, P. K., Mathur, P., Nandakumar, A., Fitzmaurice, C., Kumar, G. A., Mehrotra, R., Shukla, D.K., Rath, G. K., Gupta, P. C., Swaminathan, R., \& Thakur, J. S. (2018). The burden of cancers and their variations across the states of India: The Global Burden of Disease Study 1990-2016. The Lancet Oncology, 19(10), 1289-1306.

Edelman, B. (2004). Explaining the cost of biotech therapies. Biotechnology Healthcare, 1(2), 37.

Eniu, A., Torode, J., Magrini, N., \& Bricalli, G. (2016). Back to the 'essence'of medical treatment in oncology: The 2015 WHO Model List of Essential Medicines, ESMO Open, 1, e000030.

Ezziane, Z. (2014). Essential drugs production in Brazil, Russia, India, China and South Africa (BRICS): opportunities and challenges. International Journal of Health Policy and Management, 3(7), 365-370.

Faruqui, N., Martiniuk, A., Sharma, A., Sharma, C., Rathore, B., Arora, R. S., \& Joshi, R. (2019). Evaluating access to essential medicines for treating childhood cancers: a medicines availability, price and affordability study in New Delhi, India. BMJ Global Health, 4(2), e001379.

Giri, M., Giri, M., Thapa, R. J., Upreti, B., \& Pariyar, B. (2018). Breast Cancer in Nepal: Current status and future directions. Biomedical Reports, 8(4), 325-329.

Goldman, D. P., Joyce, G. F., Lawless, G., Crown, W. H., \& Willey, V. (2006). Benefit design and specialty drug use. Health Affairs, 25(5), 1319-1331.

Goldstein, D. A., Clark, J., Tu, Y., Zhang, J., Fang, F., Goldstein, R., Stemmer, S. M., \& Rosenbaum, E. (2017). A global comparison of the cost of patented cancer drugs in relation to global differences in wealth. Oncotarget, 8(42), 71548.

Gouglas, D., Le, T. T., Henderson, K., Kaloudis, A., Danielsen, T., Hammersland, N. C., Robinson, J. M., Heaton, P. M., \& Røttingen, J. A. (2018). Estimating the cost of vaccine development against epidemic infectious diseases: a cost minimisation study. The Lancet Global Health, 6(12), e1386e1396.

Gyawali, B. (2017). Cancer drugs in LMICs: Cheap but unaffordable. Oncotarget, 8(52), 89425-89426.

Jayasundara, K., Hollis, A., Krahn, M., Mamdani, M., Hoch, J. S., \& Grootendorst, P. (2019). Estimating the clinical cost of drug development for orphan versus non-orphan drugs. Orphanet Journal of Rare Diseases, 14(1), 12.

Kaduskar, P. U. (2016). Biosimilar insulins: an unavoidable option in South-East Asia. Indian Journal of Endocrinology and Metabolism, 20(4), 574-575.

Kalra, S., Khan, A. A., Raza, S. A., Somasundaram, N., Shrestha, D., Latif, Z. A., Bajaj, S., Pathan, M.F., Sahay, R., \& Mahtab, H. (2016). Biosimilar insulins: informed choice for South Asia. Indian Journal of Endocrinology and Metabolism, 20(1), 5-8.

Kaufman, H. L., Atkins, M. B., Subedi, P., Wu, J., Chambers, J., Mattingly, T. J., Campbell, J.D., Allen, J., Ferris, A. E., Schilsky, R. L., \& Danielson, D. (2019). The promise of Immunooncology: Implications for defining the value of cancer treatment. Journal for Immunotherapy of Cancer, 7(1), 129.
Khuluza, F., \& Haefele-Abah, C. (2019). The availability, prices and affordability of essential medicines in Malawi: A crosssectional study. PloS one, 14(2), e0212125.

Kolasani, B. P., Malathi, D. C., \& Ponnaluri, R. R. (2016). Variation of cost among anti-cancer drugs available in Indian market. Journal of Clinical and Diagnostic Research, 10(11), FC17-FC20.

Krzyszczyk, P., Acevedo, A., Davidoff, E. J., Timmins, L. M., Marrero-Berrios, I., Patel, M., White, C., Lowe, C., Sherba, J. J., Hartmanshenn, C., O'Neill, K. M., Balter, M. L., Fritz, Z. R., Androulakis, I. P., Schloss, R. S., \& Yarmush, M. L. (2018). The growing role of precision and personalized medicine for cancer treatment. Technology, 6(3 \& 4), 79-100.

Kunnumakkara, A. B., Bordoloi, D., Sailo, B. L., Roy, N. K., Thakur, K. K., Banik, K., Shakibaei, M., Gupta, S. C., \& Aggarwal, B. B. (2019). Cancer drug development: The missing links. Experimental Biology and Medicine, 244(8), 663-689.

Lexchin, J. (2013). Canada and access to medicines in developing countries: intellectual property rights first. Globalization and health, 9(1), 42.

Mohiuddin, A. K. (2019). Safety issues of biosimilar products. Pharmacology, Toxicology and Pharmaceutics Open Access Open Journal, 1(1), 6-8.

Moon, S. (2017). Powerful ideas for global access to medicines. New England Journal of Medicine, 376(6), 505507.

Moreno, S. G., \& Epstein, D. (2019). The price of innovation-the role of drug pricing in financing pharmaceutical innovation. A conceptual framework. Journal of Market Access \& Health Policy, 7(1), 1583536.

Oberoi, S. S., \& Oberoi, A. (2014). Pharmacoeconomics guidelines: The need of hour for India. International Journal of Pharmaceutical Investigation, 4(3), 109-111.

Owoeye, O., \& Owoeye, O. (2018). Biologics and Public Health: Prospects and Challenges. Journal of law and medicine, 26(1), 170-187.

Paudel, S., Owen, A. J., Owusu-Addo, E., \& Smith, B. J. (2019). Physical activity participation and the risk of chronic diseases among South Asian adults: A systematic review and metaanalysis. Scientific Reports, 9(1), 9771.

Philippidis, A. (2019). Top 15 Best-Selling Drugs of 2018: Sales for most treatments grow year-over-year despite concerns over rising prices. Genetic Engineering \& Biotechnology News, 39(4), 16-17.

Prinja, S., Bahuguna, P., Tripathy, J. P., \& Kumar, R. (2015). Availability of medicines in public sector health facilities of two North Indian States. BMC Pharmacology and Toxicology, 16(1), 43.

Ramsey, S., Blough, D., Kirchhoff, A., Kreizenbeck, K., Fedorenko, C., Snell, K., Newcomb, P., Hollingworth, W., \& Overstreet, K. (2013). Washington State cancer patients found to be at greater risk for bankruptcy than people without a cancer diagnosis. Health Affairs, 32(6), 1143-1152.

Rijal, A., Adhikari, T. B., Khan, J. A., \& Berg-Beckhoff, G. (2018). The economic impact of non-communicable diseases among households in South Asia and their coping strategy: A systematic review. PloS one, 13(11), e0205745.

Salmasi, S., Lee, K. S., Ming, L. C., Neoh, C. F., Elrggal, M. E., Khan, T. M., \& Hadi, M. A. (2017). Pricing appraisal of anticancer drugs in the South East Asian, Western Pacific and East Mediterranean region. BMC cancer, 17(1), 903.

Sankaranarayanan, R., Bhatla, N., Gravitt, P. E., Basu, P., Esmy, P. O., Ashrafunnessa, K. S., Ariyaratne, Y., Shah, A., \& Nene, 
B. M. (2008). Human papillomavirus infection and cervical cancer prevention in India, Bangladesh, Sri Lanka and Nepal. Vaccine, 26, M43-M52.

Saqib, A., Iftikhar, S., \& Sarwar, M. R. (2018). Availability and affordability of biologic versus non-biologic anticancer medicines: A cross-sectional study in Punjab, Pakistan. BMJ Open, 8(6), e019015.

Scavone, C., di Mauro, G., Mascolo, A., Berrino, L., Rossi, F., \& Capuano, A. (2019). The new paradigms in clinical research: from Early Access Programs to the novel therapeutic approaches for unmet medical needs. Frontiers in Pharmacology, 10, 111.

Scavone, C., Sportiello, L., Sullo, M. G., Ferrajolo, C., Ruggiero, R., Sessa, M., Berrino, P.M., di Mauro, G., Berrino, L., Rossi, F., \& Rafaniello, C. (2017). Safety profile of anticancer and immune-modulating biotech drugs used in a real world setting in Campania region (Italy): bio-cam observational study. Frontiers in pharmacology, 8, 607.

Siegel, R. L., Miller, K. D., \& Jemal, A. (2019). Cancer statistics, 2019. CA: a cancer journal for clinicians, 69(1), 7-34.

Simon, R. (2017). Critical review of umbrella, basket, and platform designs for oncology clinical trials. Clinical Pharmacology \& Therapeutics, 102(6), 934-941.

Stevens, H., \& Huys, I. (2017). Innovative approaches to increase access to medicines in developing countries. Frontiers in Medicine, 4, 218.

Tay-Teo, K., Ilbawi, A., \& Hill, S. R. (2019). Comparison of sales income and research and development costs for fda-approved cancer drugs sold by originator drug companies. JAMA Network Open, 2(1), e186875-e186875.
Thomas, Z., Saha, G. K., Gopakumar, K. M., \& Ganguly, N. K. (2019). Can India lead the way in neglected diseases innovation? BMJ, 364, k5396.

't Hoen, E. F. M., Kujinga, T., \& Boulet, P. (2018). Patent challenges in the procurement and supply of generic new essential medicines and lessons from HIV in the southern African development community (SADC) region. Journal of Pharmaceutical Policy and Practice, 11(1), 31.

van der Gronde, T., Uyl-de Groot, C. A., \& Pieters, T. (2017). Addressing the challenge of high-priced prescription drugs in the era of precision medicine: A systematic review of drug life cycles, therapeutic drug markets and regulatory frameworks. PloS one, 12(8), e0182613.

Vogenberg, F. R., \& Young, C. (2004). Biotech injectable drugs: Clinical applications and financial effects. Biotechnology Healthcare, 1(3), 31-40.

Wilking, N., Lopes, G., Meier, K., Simoens, S., van Harten, W., \& Vulto, A. (2017). Can we continue to afford access to cancer treatment? European Oncology and Haematology, 13(2),114119. 